\title{
1. Platform economy puzzles: the need for a multidisciplinary perspective on gig work
}

\section{Jeroen Meijerink, Giedo Jansen and Victoria Daskalova}

\section{WHAT'S IN A NAME? WHY THIS BOOK CENTERS AROUND 'PLATFORM-ENABLED GIG WORK'}

Platform-enabled gig work, that is, fixed-term activities that organizations and consumers outsource to independent contractors with the help of online labour platforms (Kuhn and Maleki 2017; Meijerink and Keegan 2019), is on the rise (Friedman 2014; Kässi and Lehdonvirta 2018; Kenney and Zysman 2016; Pesole et al. 2018). In the United Kingdom alone, more than 1.1 million individuals are reported to find gig-based work via online labour platforms, such as Uber, Deliveroo and Amazon's Mechanical Turk (Gaskell 2018) a number which is expected to rise exponentially in the future (ING-Bank 2018). Although providing benefits, such as new business development and business models, flexibility and empowerment for marginalized workers, gig work mediated by online platforms also leads to reduced (social) security for workers, precarious working conditions (including tight algorithmic control and immediate deactivation), digital divides and limited possibilities for collective action (Daskalova 2018; Frenken et al. 2020; Gandini 2019; Meijerink et al. 2019; Rosenblat 2018; Veen et al. 2020; Wood et al. 2019), which make it the subject of intense debates in policy circles and, more broadly, in society. It is precisely these puzzles, related to the opportunities and challenges associated with platform-enabled gig work, which are central to this edited volume.

Delving into these puzzles requires a clear demarcation of the phenomenon of interest to this book. The notion of platform-enabled gig work is inherently puzzling itself. This definitional puzzle becomes apparent in the variety of terms that have been coined to describe recent developments in labour markets and the rise of online labour platforms. Among others, these developments have been referred to as the gig economy (Friedman 2014; Meijerink and 
Keegan 2019; Wood et al. 2019), the platform economy (Kenney and Zysman 2016), the on-demand economy (Berg 2015; Shapiro 2018), the Uber economy (Daskalova 2018), work on demand via app (Aloisi 2016), gig work (Stanford 2017), app work (Duggan et al. 2020), crowdwork (De Stefano 2015), platform labour (Van Doorn 2017), digital labour (Fish and Srinivasan 2012; Scholz 2012), eLancing (Aguinis and Lawal 2013) and micro entrepreneurship (Kuhn and Maleki 2017).

For this book, we decided to focus on Meijerink and Keegan's (2019) term 'platform-enabled gig work'. This is not an attempt to synthesize all developments associated with the rise of online labour platforms into one overarching concept. We deliberately chose to focus on platform-enabled gig work since this term ties together the ideas that underlie the different perspectives on online labour platforms, their workers and type of economic exchanges they bring about. Specifically, the term describes the activities that manifest themselves at the intersection of gig work and platform work (or the gig economy and platform economy as economic systems in which work-related activities take place) (see Figure 1.1). For the purpose of this book, we define platform-enabled gig work as fixed-term, paid activities that are executed by independent contractors, outsourced by organizations and/or consumers, and intermediated by online labour platforms. This definition has several implications, as discussed next.

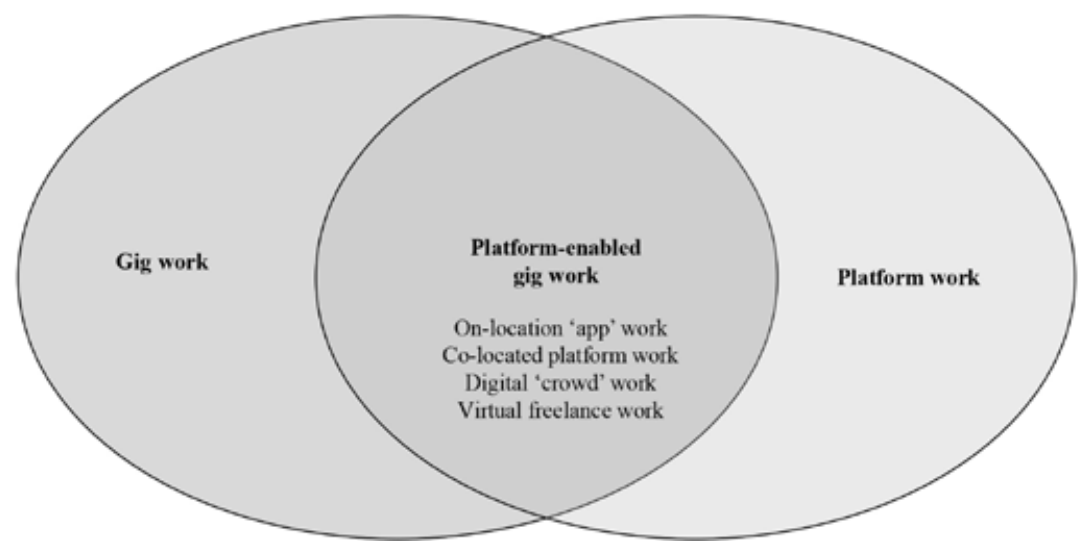

Figure 1.1 Conceptualizing platform-enabled gig work

\section{Independent Work Performed by Freelance Gig Workers}

Platform-enabled gig workers are in theory independent and, therefore, perform work outside the confines of the standard employment relationship 
(Daskalova 2018; De Stefano 2015; Duggan et al. 2020; Meijerink and Keegan 2019). That is, gig workers are not employed by an organization, but instead perform paid work as freelancers, independent contractors or solo self-employed workers (Aloisi 2016; Jansen 2017; Kuhn and Maleki 2017; Rosenblat 2018). As we see in later chapters, the legal status of many gig workers is disputed and drives many of the public and policy debates around this new type of work. From a historical perspective, this type of freelance working is far from new. For instance, as noted by Stanford (2017), contemporary forms of gig work strongly resemble the on-demand and casual work (for example, as performed by dock workers) that characterized labour markets in the nineteenth century. Moreover, freelancers now are paid per gig performed, resembling the piece-work pay that characterized 'a merchant distributed production tasks to paid employees, supplying necessary raw materials and supplies' that paid workers had to process into (semi-) finished products, such as 'textile, clothing, footwear, cutlery, small furnishings and other simple consumer good' (Stanford 2017, p. 385).

\section{Intermediation by an Online Platform}

Freelance activities that are enabled by online labour platforms are the gig work central to this edited volume. Here, online labour platforms refer to organizations that rely on the Internet and related technologies to match-make between supply and demand for labour (Kuhn and Maleki 2017; Meijerink and Keegan 2019; Stanford 2017). Online labour platforms make use of platform technology (for example, software algorithms, online applications (apps), artificial intelligence and big databases) to create online marketplaces where freelance gig workers and those who request freelance services are able to interact (Aguinis and Lawal 2013; Duggan et al. 2020; Rosenblat 2018). This makes online labour platforms a labour market intermediary that mediates between solo self-employed workers who are willing to perform activities, and organizations (in the example of business-to-business matchmaking) and/or consumers (business-to-consumer matchmaking) that wish to contract these services. Nevertheless, online labour platforms differ from other labour market intermediaries, such as temp agencies and social network sites (for example, LinkedIn). For instance, as noted by Meijerink and Keegan (2019), while temporary jobs (temp) agencies establish an employment relationship with the workers they supply to client organizations, online labour platforms do not since they work with independent contractors. Instead, online labour platforms, at least in theory, act as brokers between freelancers and those who request freelance services. Although labour market intermediaries, such as social network sites, headhunting agencies or online job boards, provide matchmaking services (Bonet et al. 2013), unlike online labour platforms they 
typically do not exert control over labour processes. The involvement of social network sites, headhunting agencies or online job boards ends when a match is made between a worker and an organization. Online labour platforms' involvement lasts longer and is more pervasive (Gandini 2019; Shapiro 2018; Veen et al. 2020) as they control gig workers by means of work practices, such as training, staffing, compensation, appraisal, incentives and task allocation (Cassady et al. 2018; Duggan et al. 2020; Meijerink and Keegan 2019).

Online labour platforms exercise control and automate work practices by means of platform technology. This involves the use of software algorithms for dispatching orders, automated deactivation, online review schemes, surveillance and/or surge pricing (Duggan et al. 2020; Kellogg et al. 2020; Rosenblat 2018; Stanford 2017; Veen et al. 2020). In so doing, algorithms augment, and at times replace, human managers in the execution of managerial activities (Raisch and Krakowski 2021). We realize that employees in employment relationships are also increasingly controlled by the same type of technologies used for controlling the labour processes of freelance platform workers (Gal et al. 2020; Leicht-Deobald et al. 2019; Strohmeier and Piazza 2015). Indeed, although employed, the meal deliverers of Takeaway.com and Foodora nevertheless perform platform work that is controlled by an algorithmic manager (Newlands 2020). Platform work is not unique to online labour platforms that match-make between freelancers and organizations/consumers. Therefore, in order to establish the research scope of the book, this edited volume centres around platform-enabled gig work as a special type of platform work performed by independent contractors. We also realize that freelancers can acquire assignments through means other than online labour platforms (for example, through their personal network). This self-acquired type of gig work is also beyond the scope of this book. Therefore, we focus on platform-enabled gig work only as freelance activities that are intermediated by online labour platforms.

\section{Fixed-term Activities: A Classification of On-demand Work via Online Labour Platforms}

In line with the freelance status of gig workers, platform-enabled gig work amounts to activities that are performed on demand (Aloisi 2016; Shapiro 2018; Van Doorn 2017). These activities can be manifold and include, among others, the delivery of food (for example, Deliveroo, Uber Eats and Instacart), driving taxi rides (Uber Rides and Lyft), cleaning (Helpling), image tagging (Amazon Mechanical Turk), programming (Upwork and Fiverr), tour guiding (Hi Hi Guide), bartending (Temper), health care (DoctoronDemand.com), babysitting (Sittercity) or consulting (GigNow and Twago). In line with the work of others (De Stefano 2015; Duggan et al. 2020; Nakatsu et al. 2014), 
we conceptualize platform-enabled gig work along two dimensions (see Figure 1.2). First, platform-enabled activities differ in the degree to which these are structured (Nakatsu et al. 2014). Structured tasks are those for which a solution to a problem or desired end-state is clearly defined. These tasks typically involve unskilled labour, job simplification, job specialization and limited worker autonomy (Wood et al. 2019). These structured activities are strictly controlled by the online labour platform and broken down into small core elements, such as the delivery of meals (Griesbach et al. 2019; Irani and Silberman 2013), image tagging (Irani and Silberman 2013) or driving taxi rides (Rosenblat 2018). Unstructured tasks are characterized by having no (clearly defined) outcome (Nakatsu et al., 2014). For executing these forms of labour, platform-enabled gig workers are provided with significant levels of job autonomy that offer the freedom and flexibility to find novel solutions (Kuhn and Maleki 2017). Platform-enabled gig work that is relatively unstructured includes graphic design, consultancy and health-care services.

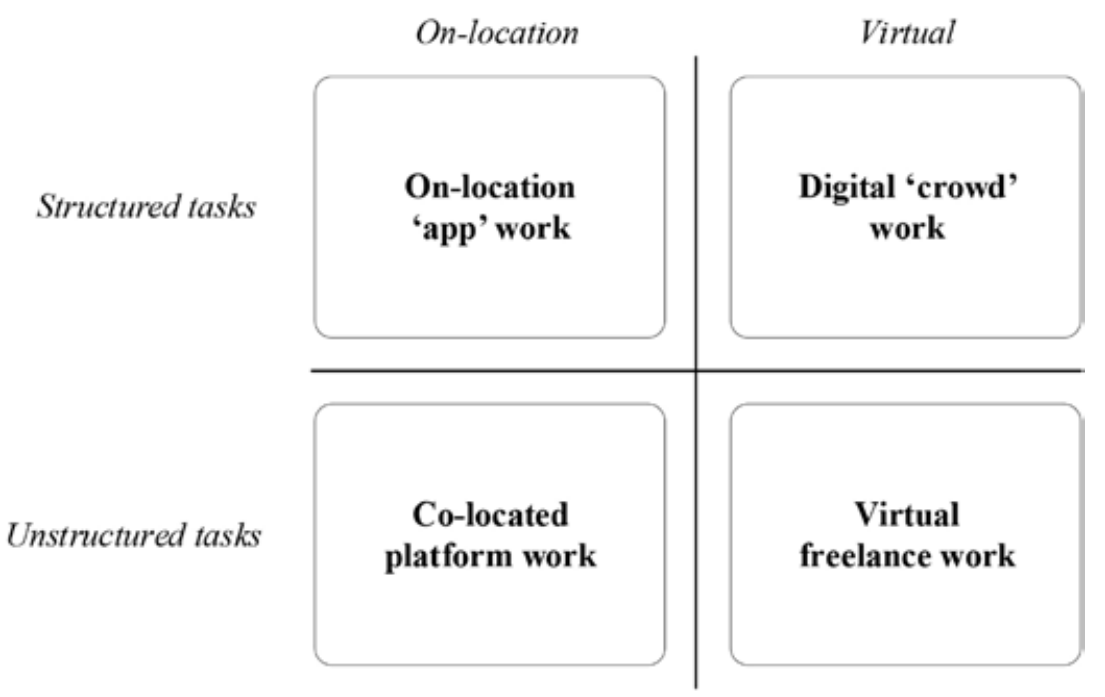

Figure 1.2 A classification of platform-enabled gig work

Second, platform-enabled gig work can be performed on location as well as virtually (Aloisi 2016; Duggan et al. 2020). In the former, the work takes place in the 'real' world. Accordingly, on-location platform work always takes place in physical interaction with others and may, depending on the complexity of the task involved, require gig workers to collaborate with other gig workers and/or employees of the hiring organization (Nakatsu et al. 2014). On-location 
activities can be both structured - what we term on-location 'app' work such as meal deliveries (Deliveroo) and driving taxi rides (Uber) - as well as unstructured - which we refer to as co-located platform work, such as consultancy services at a client's premises (for example, Twago and GigNow).

Virtual work is performed remotely from the client's premises (Jarrahi and Sutherland 2019; Lehdonvirta et al. 2019; Wood et al., 2019). Indeed, virtual gig workers and their clients are often located in different countries (Pesole et al. 2018) and rely on information technology to collaborate online (Kinder et al. 2019). Although working remotely, virtual gig workers do not necessarily work in isolation, particularly when they and their clients are mutually interdependent (Nakatsu et al. 2014). The latter occurs in virtual freelance work (see Figure 1.2) where gig workers work remotely yet have to collaborate with their clients to perform unstructured tasks (for example, graphic design via the Upwork or Fiverr platforms). Virtual work that involves the execution of structured tasks is referred to as digital crowd work, such as image tagging or online translation services (for example, via Amazon Mechanical Turk).

\section{Platform-enabled Gig Work: Beyond Mere Matchmaking}

Platform-enabled gig work involves at least three actors - workers (providers), clients (requesters) and online labour platforms (intermediaries) - who offer services to another (Meijerink et al. 2019) and are situated in wider social, economic, political and legal contexts (Frenken et al. 2020). Similar to traditional business associations (Brandl and Lehr 2019), online labour platforms (proactively) shape the social, political and legal contexts in which they operate, through lobbying activities, mobilizing their platform users for shaping public opinion (Van Doorn 2020) and/or utilizing public policies to their advantage (Meijerink et al. 2019; Uzunca et al. 2018). Moreover, online labour platforms create and/or reconfigure different markets, including: product markets (for example, food delivery, transportation, hospitality, cleaning and consultancy), labour markets where online labour platforms formalize, organize and match-make between supply and demand for labour (for example, organizing dispersed and informal labour markets), markets for intermediation services where online labour platforms compete for market share (for example, Uber, Lyft and Juno attempting to become monopolist in their respective market for intermediation), information market (that is, selling data or offering consultancy services) and, at times, financial markets (for example, taxi platforms such as Grab and Gojek which start offering financial services to their users). These markets have implications for workers, consumers, governments, organizations, labour unions, incumbent labour market intermediaries, retailers, service organizations and citizens generally. Indeed, sitting at the intersection of platform work and gig work (see Figure 1.1), platform-enabled gig work 
creates new challenges and reinforces existing challenges for societal stakeholders in unprecedented ways (for example, controlling freelancers, reclassification issues, precarity, power imbalances and privacy). It is these challenges that this edited volume addresses.

\section{OVERALL AIM OF THE BOOK: WHY A MULTIDISCIPLINARY APPROACH IS NEEDED}

The idea of a self-clearing marketplace for labour where supply meets demand is brilliant in its simplicity. Persons with resources (time, skills or spare assets) are matched with other persons (or companies) in need of someone with a particular profile. The market clears. Consumers benefit from increased choice, better matches, higher quality and, possibly, lower prices thanks to greater competition; workers enjoy more opportunities in relation to quantity, choice of different customers and potential for higher earnings. Thanks to speedy Internet connections and clever algorithms, the platform helps solve problems of coordination and allocates tasks efficiently.

Yet online labour platforms are not just the latest brilliant solution to what is fundamentally an economic problem and, arguably, a problem only for specific sectors. The online labour platform phenomenon is a game changer for labour markets generally; that is, the type of innovation which promises to disrupt (or is expected to disrupt) established ways of organizing and managing workplaces, hiring and firing, consuming and producing, and interacting and organizing. This digital revolution, possibly one of many to come, is set to upend established institutional patterns in management, social dialogue and industrial relations, labour law and social policy. This trend, and the responses it generates, raises not only practical, implementation-related questions (for example, how to ensure that self-employed workers contribute to a pension fund), but also triggers normative concerns. That is, debates concerning, for instance, Uber and its competitors are not only about making the taxi industry more efficient; they are more generally about what labour and labour institutions ought to be like in society.

Online labour platforms create or complicate a number of difficult problems for policy-makers, companies, workers and society as a whole. The nature of these problems, referred to as 'puzzles' in this book, have provided the inspiration for this multidisciplinary project. Delving into some of them briefly helps explain the editorial choices we have made as regards the scientific perspectives included, the selection of authors and topics, and the structure of the chapters. They reflect our concern with framing the gig economy developments in pragmatic, problem-driven terms, disconnected from the theoretical advances and historical experience which has accumulated over at least two centuries. 


\section{Platform Economy Puzzles}

One puzzle is the insider-outsider problem, a growing problem for labour institutions (Jansen and Lehr 2019; Lindbeck and Snower 1984; Rueda 2007). This phenomenon precedes the development of the digitally mediated gig economy; arguably, it is at the crux of the success (and fears) related to the gig economy. The insider-outsider debate fundamentally concerns the conflict between the interest of those with secure and protected jobs (insiders) and those without (outsiders), and how institutional choices create perverse incentives which exacerbate this tension (Rueda 2007). Labour institutions (including trade unions) are not able to serve all persons, nor regulate all services provided by those persons - typically, labour institutions define their target group as those who find themselves in an employment relationship. By definition this is a narrower group than the total number of people performing work in one way or another. Insiders, that is, those with a stable and well-paid job, and their representatives, arguably have limited incentives to improve opportunities for outsiders, that is, those persons looking for a job (Lindbeck and Snower 1984). By protecting only those who are already in possession of employment, the argument goes, labour institutions limit opportunities for others who wish to enter the labour market (and especially those in need of flexibility) (Emmenegger 2014). The independence, empowerment and direct access to income opportunities promised by platform companies, speaks directly to the needs of marginalized workers and especially those who are (systematically) excluded by the insider-dominated traditional labour markets.

Labour platforms solve this problem by lowering the barriers to entry of labour markets (or, some would argue, the barriers to entry for entrepreneurship; Daskalova 2018). They expand opportunities for participation in (online) labour markets. By circumventing the standard employment relationship dominated by insiders, they open up opportunities for outsiders. Partially, this is thanks to the flexibility offered by technology, which enables work to be combined with other activities or time limitations: studying, caring for children or sick relatives, or undertaking extensive medical treatment. However, the image of the platform as a democratizing force of opportunities needs to be critically examined. Does platform work solve the insider-outsider problem, or make it worse, by normalizing a second-class workforce which works under more precarious conditions for less income than insiders earn?

The insider-outsider debate leads us to another puzzle of labour market institutions, which may be termed the representation paradox. Media reports suggest that platform workers have fewer rights, greater responsibilities and lower income than their regularly employed counterparts. Despite this, platform workers shy away from union membership, a phenomenon which seems hard to square with the role that unions are expected to play on labour markets. 
In theory, unions pursue solidarity among workers (all workers, regardless of status) and are tasked to take action to improve the labour conditions of all workers, not only those among their membership. Paradoxically, unions, whose membership has been declining in the past decade, have shown some reluctance to represent atypical workers (Jansen and Lehr 2019), which often include platform workers. In response to this, alternative, grass-root forms of worker representation and organizing are emerging - both within the platforms themselves and in the form of worker cooperatives (Scholz 2012). Yet how likely are these alternative forms of representation to succeed? Can we expect to see new actors emerge, or even replace, established players in the field of industrial relations? A look back to history and theory, combined with insights from data on the gig economy, can help. Online labour platforms expose the difficulties inherent in organizing workers whose interests differ and may even be diametrically opposed. After all, labour markets are populated by individuals with different skills, needs and limitations (including personal obligations and geographic locations) who nonetheless all compete for generally standardized occupations. These difficulties in organizing suggest a fragmentation of representative institutions, while the very presence of labour platforms undermine the legitimacy and thereby weaken the power of regular unions. This raises the question of what the future of social dialogue and industrial relations will look like, and whether the creative destruction ushered in by the platform revolution will replace old actors with new actors, or simply upend the existing arrangements without generating viable alternatives.

Turning to the nature of platform work itself and how it is experienced by individual workers, there are also puzzling inconsistencies between narrative and reality to be found. Technology-optimistic narratives emphasize that they bring freedom and empowerment to platform workers owing to flexibility in scheduling, the absence of a manager ('Be your own boss!') and increased autonomy ('You decide when and how much to work'). However, media reports and academic publications have quickly dispelled these claims (Aloisi 2016; Rosenblat 2018; Wood et al. 2019). A physically present human boss may be oppressive but, apparently, so is the ubiquitous presence of an invisible algorithm. Whereas the traditional systems of control linking worker to management are virtually erased, new and less well known forms of control algorithmic management and user reviews - are now in control (Kellogg et al. 2020). The management of work may thus only seem free from human bias in hiring, firing and workplace management, but the reality is that the algorithm is not flawless; multiple studies note evidence of algorithms reproducing societal hierarchies and biases (Faraj et al. 2018; Leicht-Deobald et al. 2019; Pasquale 2015; Zuboff 2019). Being your own boss is attractive as regards making decisions, but it also comes with greater responsibility for your own financial and legal liabilities (such as responsibility for worker accidents or 
damage to a client's property). Workers may seem independent; however, they are embedded in a particular technological and business ecosystem (Frenken et al. 2020; Friedman 2014). The flattening of this organization is anything but apparent. For workers attracted to the idea of entrepreneurship and autonomy, this realization raises the question of empowerment: to what extent does their freelance status help them advance, or does it also emasculate them? One of the paradoxes of labour platforms lies in this guarded promise toward workers to enhance their autonomy by subjecting them to algorithmic management (Gandini 2019; Shapiro 2018). It is worth asking, is the algorithm gentler, more generous and more forgiving than a flesh-and-blood manager? Similarly, the supposed freedom brought about by platforms may be questioned, given the need for income, and the conditional and uncertain nature of income. The technology needs to be seen in context. As an old joke goes, 'The perks of the job: you can work whenever you want; every day is a Saturday; the cons: you work on Saturday'.

\section{The Objective of this Volume}

The changes outlined previously are important; all the more so because they are far reaching. Labour market institutions and concepts such as labour law, collective bargaining and the notion of human resource management are under pressure owing to these developments in online labour platforms (Aloisi 2016; Berg 2015; De Stefano 2015; Frenken et al. 2020; Meijerink and Keegan 2019). Perceptions and experiences of individuals (regarding empowerment, precariousness and representation) shape responses from workers and employers, but also from policy-makers and citizens. Currently, research into platform-enabled gig work is dispersed across a number of fields, such as law, labour economics, sociology, history and technology, geography, new media studies, business, human resource management, work and organizational psychology, and entrepreneurship (Sutherland and Jarrahi 2018). However, the puzzles associated with platform-enabled gig work are far from mono-disciplinary in nature. The same applies to reaping the benefits of gig work and turning its potential into real value for workers, platform firms and other societal stakeholders. Policy responses as well as academic literature on the topic often tend to focus on national circumstances, and often on specific issues which need to be addressed with some urgency. However, the changes in labour markets are deeper and call for a broader perspective, a sense of context and a comparative perspective. Explaining the gig work phenomenon and designing responses to it requires knowledge of these different labour market institutions and their interaction with platforms and platform workers. This requires a multidisciplinary perspective on the drivers and nature of the puzzles associated with platform-enabled gig work, and the implications (both 
desired and undesired) for societies, labour markets, public policy organizations and individuals. Accordingly, this book embarks on a perilous task by offering a multidisciplinary perspective on platform-enabled gig work and the implications (both intended and unintended) this has for societies, labour markets, public policy organizations and individuals. We are certain to miss some important disciplinary perspectives and we can only offer snippets from different disciplinary contributions, but we nonetheless believe we have taken an important step forward in opening the space for multidisciplinary dialogue on the topic of platform work.

\section{APPROACH AND OUTLINE OF THE BOOK}

This volume takes stock of and synthesize insights from different academic disciplines on past and future challenges as well as opportunities associated with platform-enabled gig work. In doing so, the book explores whether established theories are useful to understand the major puzzles of the platform economy, and how theory, research and policy on platform-enabled gig work may be advanced. Bringing together different strands of research will provide a bird's-eye view of developments and will enable fresh perspectives on the possibilities and problems faced by policy-makers, unions, industry and business, and, more broadly, society.

To ensure complementarities across the different chapters, and to foster readability, each chapter is structured similarly, whereby each chapter reflects on the following issues as seen from the selected academic disciplines that study gig work. First, each chapter revolves around a specific problem (a puzzle) that reflects either an urgent societal issue or an academic question. Second, each chapter discusses the causes and consequences of the problem at hand. Based on these insights, the authors discuss potential solutions to either fill the knowledge gap in the literature and/or offer practical policy recommendations. Finally, each chapter presents directions for future research.

This volume consists of three parts. Part I sets the stage by placing platform-mediated gig work in a broader context. First, in Chapter 2, Annarosa Pesole discusses the conceptual and methodological problem of measuring platform-enabled gig work in labour economics. Empirically investigating platform labour is, in the words of Huws et al. (2017, p. 52) 'a step into the unknown' as there is no consensus on definitions and no existing baseline data nor any established method of collecting it. The basic question of how prevalent platform-mediated gig work really is, therefore is more complex than it seems. To date, most data on platform work is anecdotal or relies on small-scale qualitative studies. In particular, quantitative and comparative data on platform labour are limited. Pesole's chapter discusses the advantages and disadvantages of different approaches for collecting data on the prevalence 
and nature of platform work. After discussing measurement approaches, she reports findings on the size and nature of platform work in Europe based on data from the COLLEEM survey by the European Commission's Joint Research Centre (JRC).

In Chapter 3, Jim Stanford raises the issue of how novel platform-mediated gig work really is. Despite being promoted as a technologically-driven and innovative work practice, Stanford provides a historical perspective on platform labour and argues that the core features of digitally mediated gig work are hundreds of years old, having been applied in pre-digital modes of capitalism. In this chapter, Stanford argues that gig work is better understood as a return to previous practices, instead of a new model of employment, and is part of a wider increase in insecure and non-standard work under neoliberalism. He also argues that not just technology, but also economic, political and social determinants condition the prevalence of insecure and non-standard labour.

In Chapter 4, Victoria Daskalova, Shae McCrystal and Masako Wakui take a legal perspective. They argue that platform-mediated gig work revives some old problems regarding regulating labour markets while simultaneously challenging existing legal solutions to those problems. One of the key puzzles in the platform economy is to do with legal classifications: are platform workers independent contractors or are they employees in disguise? This chapters discusses the tension between two legal fields. On the one hand, is labour law and collective bargaining, the traditional legal solutions to protect workers against social and labour risks. On the other, is commercial law, including competition law. The latter, although originally developed to fight concentrations of power in cartels, often raises barriers to collective bargaining by self-employed workers.

Part II of this book addresses puzzles in economic and social exchanges in the platform-enabled gig economy. In Chapter 5, Aaron Shapiro addresses the question of why urban areas are an attractive source of (economic) value for online platform firms. He discusses how platforms utilize the accessibility and collective utility of urban infrastructures. Building on urban theory, Shapiro introduces the notion of infrastructural surplus. In particular, he discusses two modes by which platforms may extract value from urban infrastructures: reformatting social space and transactional exclusion. The former involves platforms directly reformatting social space as an infrastructural support for their operations; the latter captures infrastructural surplus indirectly, by excluding resources necessary to perform gigs from the platform-mediated labour transaction.

Chapter 6 by Niels van Doorn and Adam Badger also focuses on value extraction. The puzzle they address is how gig economy companies can continue to grow despite regularly suffering substantial losses. To conceptualize this puzzle, Van Doorn and Badger introduce the notion of dual value pro- 
duction, which describes how platforms capture two types of value from gig work: the monetary value associated with the service transaction, and the more speculative value associated with the data generated during service provision by gig workers. By elaborating on the construction of data as a specific asset class, this chapter examines platform-enabled gig work from the perspective of political economy of data and finance capital.

In Chapter 7, Anne Keegan and Jeroen Meijerink discuss how gig work mainly takes place outside the confines of an employment relationship, while most gig workers are nevertheless subject to a range of human resource management (HRM) activities (such as recruitment, selection, appraisal, compensation and job design) that traditionally are seen to uphold employment relationships. It is this puzzle - HRM activities without employment relationships - that is central to this chapter. From the perspective of HRM scholarship, Keegan and Meijerink examine why the business model of online labour platforms, and the platform ecosystems they create, requires the use of HRM activities and how this creates institutional complexity. Moreover, they explore the consequences of the institutional complexity for gig workers, platforms and societal stakeholders.

Chapter 8 by James Duggan, Ultan Sherman, Ronan Carbery and Anthony McDonnell focuses on the multi-party working relationships between platform firms, gig workers and consumers or hiring organizations. The problem this chapter starts out with is that in platform labour the traditional concept of a legal employment relationship between an employer and employee is increasingly less applicable. Drawing from the fields of work and organizational psychology, Duggan and colleagues adopt an alternative perspective to understand employment relationship in the platform economy: the psychological contract. Psychological contract theory examines the mutual promise-based expectations that parties have of one another and how these implicit expectations impact behaviour. Using psychological contract theory, this chapters examines the (relational and transactional) expectations that may exist in the working relationships between gig workers, the platform firms for whom they work, and consumers or hiring organizations.

Part III of this book explores the wider social and political implications of platform-mediated gig work. In particular, this part of the book looks into collective organization and interest representation. First, in Chapter 9, Damion Jonathan Bunders examines the puzzle of collective action. This chapter builds on insights from sociology and social history to examine how gig workers themselves might strive for better work. Yet, while standard sociological theory would dictate that individualized work practices of platform workers hinder collective organization, Bunders shows that various forms of collective action by gig workers can be observed in practice. As an extreme case of collective action, this chapter discusses worker-owned platform cooperatives. 
Bunders compares worker-owned gig platforms with traditional worker cooperatives in order to derive insights on the chances for collective action in the platform economy.

Chapter 10, shifts the focus from self-organization to interest representation. In this chapter Paul Jonker-Hoffrén and Giedo Jansen discuss how digital platform-based work challenges existing models of interest representation, which are often based the notions of place-based citizenship (that is, political representation) and/or type-of-contract segmentation (that is, representation in a country's systems of industrial relations). Combining insights from political science and industrial relations, Jonker-Hoffrén and Jansen argue that representation of platform workers is a function of both demand for and supply of representation. They present a framework, based on insider-outsider theory, through which representation by political parties, trade unions and other interested organizations can be studied.

Finally, in Chapter 11, we as editors synthesize the book by integrating insights on the causes, consequences and (policy) solutions to the various platform economy puzzles as outlined in the different chapters of this volume. We also identify avenues for future interdisciplinary research into the challenges and opportunities of platform-enabled gig work. To ensure the implementation of our proposed research avenues, we conclude with a discussion of methodologies and data collection techniques for new research into platform economy puzzles.

\section{REFERENCES}

Aguinis, H. and S.O. Lawal (2013), 'eLancing: a review and research agenda for bridging the science-practice gap', Human Resource Management Review, 23 (1), 6-17.

Aloisi, A. (2016), 'Commoditized workers: Case study research on labor law issues arising from a set of on-demand/gig economy platforms', Comparative Labor Law and Policy Journal, 37 (3), 653-90.

Berg, J. (2015), 'Income security in the on-demand economy: findings and policy lessons from a survey of crowdworkers', Comparative Labor Law and Policy Journal, 37 (3), 543-76.

Bonet, R., P. Cappelli and M. Hamori (2013), 'Labor market intermediaries and the new paradigm for human resources', Academy of Management Annals, 7 (1), 341-92.

Brandl, B. and A. Lehr (2019), 'The strange non-death of employer and business associations: an analysis of their representativeness and activities in Western European countries', Economic and Industrial Democracy, 40 (4), 932-53.

Cassady, E.A., S.L. Fisher and S. Olsen (2018), 'Using eHRM to manage workers in the platform economy', in J.H. Dulebohn and D.L. Stone (eds), The Brave New World of eHRM 2.0, Charlotte, NC: Information Age, pp. 217-46.

Daskalova, V. (2018), 'Regulating the new self-employed in the Uber economy: what role for EU competition law', German Law Journal, 19 (3), 461-508. 
De Stefano, V. (2015), 'The rise of the just-in-time workforce: on-demand work, crowdwork, and labor protection in the gig-economy', Comparative Labor Law and Policy Journal, 37 (3), 471-504.

Duggan, J., U. Sherman, R. Carbery and A. McDonnell (2020), 'Algorithmic management and app-work in the gig economy: a research agenda for employment relations and HRM', Human Resource Management Journal, 30 (1), 114-32.

Emmenegger, P. (2014), The Power to Dismiss: Trade Unions and the Regulation of Job Security in Western Europe, New York: Oxford University Press.

Faraj, S., S. Pachidi and K. Sayegh (2018), 'Working and organizing in the age of the learning algorithm', Information and Organization, 28 (1), 62-70.

Fish, A. and R. Srinivasan (2012), 'Digital labor is the new killer app', New Media and Society, 14 (1), 137-52.

Frenken, K., T. Vaskelainen, L. Fünfschilling and L. Piscicelli (2020), 'An institutional logics perspective on the gig economy', in I. Maurer, J. Mair and A. Oberg (eds), Theorizing the Sharing Economy: Variety and Trajectories of New Forms of Organizing, Bingley: Emerald.

Friedman, G. (2014), 'Workers without employers: shadow corporations and the rise of the gig economy', Review of Keynesian Economics, 2 (2), 171-88.

Gal, U., T.B. Jensen and M.-K. Stein (2020), 'Breaking the vicious cycle of algorithmic management: a virtue ethics approach to people analytics', Information and Organization, 30 (2), art. 100301.

Gandini, A. (2019), 'Labour process theory and the gig economy', Human Relations, 72 (6), 1039-56.

Gaskell, A. (2018), 'The Demographics of the gig economy', Forbes, 1 August, accessed 9 December 2020 at https://www.forbes.com/sites/adigaskell/2018/08/01/ the-demographics-of-the-gig-economy/\#6d7306b969fb.

Griesbach, K., A. Reich, L. Elliott-Negri and R. Milkman (2019), 'Algorithmic control in platform food delivery work', Socius, 5 (1), 1-15.

Huws, U., N. Spencer, D.S. Syrdal and K. Holts (2017), Work in the European Gig Economy: Research Results from the UK, Sweden, Germany, Austria, the Netherlands, Switzerland and Italy, Brussels: Foundation for European Progressives Studies.

ING-Bank (2018),'Platformen Kunnen Arbeidsmarkt Drastisch Veranderen' ('Platforms can change the labor market drastically') accessed 9 December 2020 at https://www.ing.nl/media/pdf-EBZ-Platformen\%20kunnen\%20arbeidsmarkt\%20dr astisch\%20veranderen_tcm162-159443.pdf.

Irani, L.C. and M.S. Silberman (2013), 'Turkopticon: interrupting worker invisibility in Amazon Mechanical Turk', in Proceedings of the SIGCHI Conference on Human Factors in Computing Systems (CHI '13), New York: Association for Computing Machinery, pp. 611-20, doi:10.1145/2470654.2470742.

Jansen, G. (2017), 'Farewell to the rightist self-employed? "New self-employment" and political alignments', Acta Politica, 52 (3), 306-38.

Jansen, G. and A. Lehr (2019), 'On the outside looking in? A micro-level analysis of insiders' and outsiders' trade union membership', Economic and Industrial Democracy, 23 December, accessed 12 April 2021 at https://doi.org/10.1177 \%2F0143831X19890130.

Jarrahi, M.H. and W. Sutherland (2019), 'Algorithmic management and algorithmic competencies: understanding and appropriating algorithms in gig work', in N. Taylor, C. Christian-Lamb, M. Martin and B. Nardi (eds), Information in Contemporary Society, Cham: Springer, pp. 578-89. 
Kässi, O. and V. Lehdonvirta (2018), 'Online labour index: measuring the online gig economy for policy and research', Technological Forecasting and Social Change, 137 (December), 241-8.

Kellogg, K.C., M.A. Valentine and A. Christin (2020), 'Algorithms at work: the new contested terrain of control', Academy of Management Annals, 14 (1), 366-410.

Kenney, M. and J. Zysman (2016), 'The rise of the platform economy', Issues in Science and Technology, 32 (3), 61-9.

Kinder, E., M.H. Jarrahi and W. Sutherland (2019), 'Gig platforms, tensions, alliances and ecosystems: an actor-network perspective', Proceedings of the ACM on Human-Computer Interaction, 3 (November), art. 212, doi:10.1145/3359314.

Kuhn, K.M. and A. Maleki (2017), 'Micro-entrepreneurs, dependent contractors, and instaserfs: understanding online labor platform workforces', Academy of Management Perspectives, 31 (3), 183-200.

Lehdonvirta, V., O. Kässi, I. Hjorth, H. Barnard and M. Graham (2019), 'The global platform economy: a new offshoring institution enabling emerging-economy microproviders', Journal of Management, 45 (2), 567-99.

Leicht-Deobald, U., T.Busch, C. Schank, A. Weibel, S. Schafheitle, I. Wildhaber, et al. (2019), 'The challenges of algorithm-based HR decision-making for personal integrity', Journal of Business Ethics, 160 (2), 377-92.

Lindbeck, A. and D.J. Snower (1984), Involuntary Employment as an Insider-Outsider Dilemma, Stockholm: Institute for International Economic Studies.

Meijerink, J.G. and A. Keegan (2019), 'Conceptualizing human resource management in the gig economy: toward a platform ecosystem perspective', Journal of Managerial Psychology, 34 (4), 214-32.

Meijerink, J.G., A. Keegan and T. Bondarouk (2019), 'Exploring "human resource management without employment" in the gig economy: how online labor platforms manage institutional complexity', paper presented at the Sixth International Workshop on the Sharing Economy, Utrecht, 28-29 June.

Nakatsu, R.T., E.B. Grossman and C.L. Iacovou (2014), 'A taxonomy of crowdsourcing based on task complexity', Journal of Information Science, 40 (6), 823-34.

Newlands, G. (2020), 'Algorithmic surveillance in the gig economy: the organisation of work through Lefebvrian conceived space', Organization Studies, 9 July, accessed 2 April 2021 at https://doi.org/10.1177\%2F0170840620937900.

Pasquale, F. (2015), The Black Box Society, Cambridge, MA: Harvard University Press.

Pesole, A., M. Brancati, E. Fernández-Macías, F. Biagi and I. González Vázquez (2018), Platform Workers in Europe, Luxembourg: Publications Office of the European Union.

Raisch, S. and S. Krakowski (2021), 'Artificial intelligence and management: the automation-augmentation paradox', Academy of Management Review, 46 (1), 192-210.

Rosenblat, A. (2018), Uberland: How Algorithms Are Rewriting the Rules of Work, Oakland, CA: University of California Press.

Rueda, D. (2007), Social Democracy Inside Out: Partisanship and Labor Market Policy in Advanced Industrialized Democracies, Oxford: Oxford University Press.

Scholz, T. (2012), Digital Labor: The Internet as Playground and Factory, New York: Routledge.

Shapiro, A. (2018), 'Between autonomy and control: strategies of arbitrage in the “on-demand" economy', New Media and Society, 20 (8), 2954-71.

Stanford, J. (2017), 'The resurgence of gig work: historical and theoretical perspectives', Economic and Labour Relations Review, 28 (3), 382-401. 
Strohmeier, S. and F. Piazza (2015), 'Artificial intelligence techniques in human resource management - a conceptual exploration', in J. Kacprzyk and L. Jain (eds), Intelligent Techniques in Engineering Management, New York: Springer, pp. 149-72.

Sutherland, W. and M.H. Jarrahi (2018), 'The sharing economy and digital platforms: a review and research agenda', International Journal of Information Management, 43 (December), 328-41.

Uzunca, B., J.C. Rigtering and P. Ozcan (2018), 'Sharing and shaping: a cross-country comparison of how sharing economy firms shape their institutional environment to gain legitimacy', Academy of Management Discoveries, 4 (3), 248-72.

Van Doorn, N. (2017), 'Platform labor: on the gendered and racialized exploitation of low-income service work in the "on-demand" economy', Information, Communication \& Society, 20 (6), 898-914.

Van Doorn, N. (2020), 'A new institution on the block: on platform urbanism and Airbnb citizenship', New Media and Society, 22 (10), 1808-26.

Veen, A., T. Barratt and C. Goods (2020), 'Platform-capital's "app-etite" for control: a labour process analysis of food-delivery work in Australia', Work, Employment and Society, 34 (3), 388-406.

Wood, A.J., M. Graham, V. Lehdonvirta and I. Hjorth (2019), 'Good gig, bad gig: autonomy and algorithmic control in the global gig economy', Work, Employment and Society, 33 (1), 56-75.

Zuboff, S. (2019), The Age of Surveillance Capitalism: The Fight for a Human Future at the New Frontier of Power, New York: Public Affairs. 